DOI: 10.17805/ggz.2019.6.2

\title{
От трагического героя к травматической истории: к проблематике позднего К. Марло («Эдуард IІ», «Парижская резня»)
}

\section{B. С. Макаров}

Православный Свято-Тихоновский гуманитарный университет, г. Москва

Сложность начала 1590-х г2. как периода в истории развития английского театра и литературы в том, что происходят значительные перемены в популярных у зрителей драматических жанрах, где на одно из первых мест выходит хроника - жанр, в котором К. Марло успел сделать не так много, его достижения не так заметны и продолжены новыми драматургами прежде всего У. Шекспиром. Изучение «поздних пьес» Марло показывает его отход от трагедии, построенной вокруг одного героя, которого Г. Левин определил термином “оverreacher”, и переход к поэтике, которую М. Мартин не совсем удачно, но в целом точно назвал «травматическим реализмом». Марло исследует ситуацию насилия уже не в вымышленно-трагедийных, а в исторических обстоятельствах, где память о травмирующем насилии сохраняется, воспроизводится, а возможно, и смягчается в сообществах памяти.

Ключевые слова: К. Марло; «Эдуард II»; «Парижская резня»; травма; историческая память; сообщества памяти

\author{
From the Tragic Hero to Traumatic History: \\ Towards the Problems of C. Marlowe's "Late Plays" \\ ("Edward II", “The Massacre at Paris") \\ V. S. Makarov \\ St. Tikhon's Orthodox University, Moscow
}

\footnotetext{
* Статья подготовлена в рамках проекта «Кристофер Марло и его творчество в русской и мировой культуре: междисциплинарный взгляд» при финансовой поддержке Российского фонда фундаментальных исследований (грант № 18-012-00679).

The article was prepared within the framework of the project "Christopher Marlowe and His Literary Heritage in Russian and World Culture: An Interdisciplinary Look” with financial support from the Russian Foundation for Basic Research (grant no. 18-012-00679).
} 
Early 1590s are a difficult period in the history of English theatre and literature in the sense that they saw a radical change in popular stage genres. One of the most powerful metamorphoses happened to the "histories" - a genre where Christopher Marlowe did not excel himself, and his achievements are less conspicuous and have been coming simultaneously with the aspiring playwrights like William Shakespeare. Studying Marlowe's late plays reveals his departure from the community-free tragedy focused on a single hero of the type Harry Levin termed "overreacher". Instead Marlowe turnes to a kind of poetics that Matthew Martin somewhat heavy-handedly, but on the whole, aptly termed "traumatic realism". Marlowe now focuses on troubling violence in historical circumstances, rather than that in imaginary setting of a tragedy. By arranging his material for his audience, Marlowe helps the memory of traumatic violence sustain, reproduce and maybe mitigate itself in the communities of memory.

Keywords: C. Marlowe; "Edward II"; "Massacre at Paris”; trauma; historical memory; communities of memory

\section{ВВЕДЕНИЕ}

Идею периодизации творчества К. Марло нередко критикуют, и действительно, ее затрудняют несколько факторов - краткость литературной карьеры драматурга (около 6 лет от переезда в Лондон из Кембриджа до гибели), отсутствие точной датировки пьес, а также малый размер марловского канона. Тем не менее, сейчас у исследователей почти не остается сомнений, что по крайней мере две пьесы Марло - «Парижская резня» и «Эдуард II» — написаны в период между 1591 и началом 1593 г. ${ }^{1}$. К тому времени уже были написаны и изданы обе части «Тамерлана», скорее всего, также и «Мальтийский еврей», и «Доктор Фауст». Но, действительно, хронологический разрыв здесь пренебрежимо ничтожный.

Важнее другое. Во-первых, как неоднократно отмечалось (см., напримep: Wiggins, 2000: 22-23), начало 1590-х гг. — время, когда в жанровую систему английской драмы врывается историческая хроника. Наряду с трагедией мести, этот жанр предлагает сцене новый тип исторического мышления, связанный, помимо прочего, с травмой и памятью о ней.

Во-вторых, даже предварительная попытка (а большей целью в этой статье я не задаюсь) рассмотреть поздние трагедии Марло может быть важна

\footnotetext{
${ }^{1} \mathrm{O}$ проблемах их датировки см. комментарии, подготовленные в ходе работы над данным проектом (Макаров, 2018b; 2019), а также нашу статью о возможной датировке «Фауста» (Макаров, 2018a).
} 
для преодоления одностороннего «мифобиографического» (в терминах Н. В. Захарова - см.: Захаров, 2018) подхода к его жизни и творчеству. Размер марловского канона и интенсивность его краткого пути заметно способствуют идентификации героя-overreacher'a и самого Марло. На этом и строится отмирающий биографический миф, постепенно уходящий сейчас в массовую культуру.

Однако важно при этом не создать новый миф о какой-то «новой стадии» марловского творчества, а потому наше внимание к двум поздним пьесам Марло потенциально необходимо вчитать в жанровую историю английской драмы. Это слишком большая задача для короткого текста, но предложить какое-то решение для нее в дальнейшем будет необходимо. Остановимся пока на гипотетическом предположении, что в «ранних» трагедиях Марло (от «Дидоны» до «Мальтийского еврея») есть нечто способствующее «подключению» исторической хроники к трагическому материалу.

Но прежде несколько слов о недавней теории, что Марло мог быть соавтором шекспировских хроник. Впервые она была развернута Х. Крэйгом (Craig, 2009) и стала базовой для редакторов New Oxford Shakespeare. Соавторство Марло, возможность которого ученые упоминали ранее в связи с текстуальными совпадениями, было показано на основании компьютерного анализа частотных словосочетаний. Противоположную сторону в споре занял Д. Фрибери-Джонс, отстаивающий возможность частичного «бессознательного повторения» (“unconscious repetition”; Freebury-Jones, 2017: 137) ряда структур, в том числе марловских. Фрибери-Джонс выполнил анализ по своему набору словоформ и не пришел к выводу, что соавторство стопроцентно доказано.

Какой бы выгодной идея соавторства не казалась с нашей позиции, я предлагаю пока остановиться на жанровых проблемах, прежде всего из-за опасности нового витка «мифобиографии» - достаточно вспомнить, с каким некритическим энтузиазмом идею соавторства Марло и Шекспира приняли марловианцы.

\section{ПОЭТИКА ТРАГЕДИЙ К. МАРЛО}

Вернемся к гипотезе о сплаве трагедийного и исторического или, точнее, переносе наработанного трагедией опыта на историческую тему (причем чаще всего взятую из истории средневековой Англии). Для ренессансных поэтик было общим местом указывать, что короли и их судьбы (т. н. традиция “de casibus”) — лучший материал для трагедии. Современные исследователи 
столь же часто связывают появление исторической хроники как жанра со вторым изданием «Хроник» Р. Холиншеда (1587) и с проникновением на сцену духа «национального подъема» после разгрома Непобедимой армады, вследствие чего часто приписывают театральным хроникам важную роль в «тюдоровской пропаганде».

Классический образец такого прочтения - введение Дж. Доллимора к заслуженно знаменитой книге «Политический Шекспир» (“Political Shakespeare”). Доллимор совершенно прав, резко критикуя Э. М. У. Тилльярда за то, что он не замечает, что сконструированный им самим метафизический «елизаветинский миропорядок» существует не в вакууме, а на театральной сцене, где речи о нем произносят не вестники богов, а персонажи со своей позицией и прагматическими целями. Доллимор видит в «дидактическом акценте» (“didactic stress”) в том числе и «стратегию идеологической борьбы» (“a strategy of ideological struggle”), и «обеспокоенность... социальными силами, в которых видели угрозу» (“an anxious reaction to emergent and (in)subordinate social forces which were perceived as threatening”; Dollimore, 1994: 5) Чуть ниже Доллимор цитирует знаменитую фразу Л. Стоуна об «истерическом требовании порядка любой ценой» ("hysterical demand for order at all costs"; ibid). K сожалению, Доллимор, в отличие, скажем, от С. Гринблатта, редко проводит границу между теми социальными акторами, которые могут заказать и оплатить пьесу, и теми, которые вполне способны и сами написать ее, и высказать в ней собственные «требования порядка», возможно, обращенные совсем не к непокорным «низшим» социальным силам. Как и в случае с компьютерным доказательством авторства, в «антропоморфном пейзаже» биографизма крайне трудно разделить жанр и автора. Говоря о том, что трагедии Марло стали пространством поиска и постоянного конструирования трансгрессии - в интеллектуальном поиске (Фауст), политической практике (Тамерлан и Гиз) и т. д. - мы должны учитывать, что мифологизированный Марло-борец и жертва, новый Фаэтон, остается востребован там и тогда, где в трансгрессии видится способ обхода или преодоления запретов.

Итак, что же в поэтической практике марловской трагедии, вне зависимости от ее трансгрессивных апроприаций неоромантиками, современной массовой культурой и т. д., способствует ее связи с исторической хроникой?

Прежде всего, как мне кажется, это историчность самой его трагедии. Кроме ранней «Дидоны, царицы Карфагенской» (хотя можно вспомнить, что сына Энея - Брута - считали основателем государственности на Британских островах), во всех трагедиях драматурга присутствует мотив памяти о 
делах героя. Тамерлан способен запретить помнить об уничтоженном им городе, где умерла Зенократа, оставив на его месте столп с надписью на трех языках (III, 2). Фауст в последней мольбе мечтает стереть память о себе, а Варавва, готовясь уничтожить всех насельников монастыря, с гневом отбрасывает мысль о забвении:

That I may vanish ore the earth in ayre, And leave no memory that e're I was.

(Marlowe, 1995: 18)

Как бы то ни было, все эти марловские overreachers более или менее успешно пытаются устанавливать режим памяти о себе. Память о Тамерлане контролируют его дети, и в самой пьесе не находится критика, который подверг бы ее детальному разбору. Приговор Варавве и Фаусту произнесен - в последнем случае это приговор метафизических сил, лежащих вне этого мира, в первом - его собственный несработавший план, но Варавва успевает раскрыть свое злодейство и Фернезе, и Калимату. Наказание всех героев неизбежно, но наказывающие их либо вынесены за пределы человеческого, либо не могут встать рядом с героями. Фернезе побеждает, Мальта свободна от осады, но какой герой добился этого, если не Варавва с его патологической ненавистью одновременно к христианам и мусульманам?

Важную черту такого режима памяти выдает Макиавель в прологе к «Мальтийскому еврею». Выступая в качестве некоего дьявольского духа, способного переселяться из души в душу (так, он прилетает к зрителям, освобожденный от тела недавно убитого Гиза), Макиавель, в сущности, признает право исторической памяти лишь за собой и своими последователями:

Though some speake openly against my bookes,

Yet will they reade me, and thereby attaine

To Peters Chayre: And when they cast me off,

Are poyson'd by my climing followers.

I count Religion but a childish Toy,

And hold there is no sinne but Ignorance.

Birds of the Aire will tell of murders past;

I am asham'd to heare such fooleries... 
Люди и общества проживают в состоянии зависти и злобы, но изменить свое положение могут, лишь обратившись к книгам Макиавеля, преодолевая свое «невежество» и учась манипулировать. Сколько бы о прошлых убийствах не «пели птицы» (т. е. поэты), ситуацию это не изменит - вот в чем смысл «лекции» Макиавеля в Англии. Разумеется, не следует утверждать, что с этой позицией Марло хоть в какой-то степени солидаризируется: скорее он пытается создать такое сообщество памяти из зрителей.

Человеку XXI, постгулаговского и постосвенцимского, столетия трудно видеть в Тамерлане только «бич Божий», современному зрителю хочется крикнуть, что он нарушит запрет и запомнит название города. Смерть Тамерлана у него вызывает примерно те же чувства, что и гибель Вараввы в кипящем котле. Вряд ли зритель Лондона XVI в. видел ситуацию абсолютно так же, но и он оставался участником помнящего сообщества, знавшего, как спаслась Мальта и пали государства Востока.

Но таких сообществ нет внутри первых трех трагедий. В тексте А «Фауста» разве что только деперсонализированный Старик (вспомним, что в немецкой народной книге и ее английском переводе он - состоятельный и благочестивый сосед Фауста, а не аллегорический герой) понимает, что происходит с доктором. Его коллеги узнают все в последний момент и не могут помочь ему обратиться к Богу (в тексте Б они хотя бы видят мрачную картину после его гибели). Мальта и пространства Востока из-за злодейств Вараввы и Тамерлана «обезлюдели» и лишены сообществ, играющих хоть какуюто роль в их жизни.

Конфликты в Англии Эдуарда II и религиозные войны поздних Валуа также скопом уничтожают толпы героев. В сцене 2 «Резни» Гиз за несколько минут успевает отдать приказ отравить вдовствующую королеву Наваррскую и застрелить Колиньи, в сцене 3 оба события происходят в течение нескольких минут. В сценах 7-10 протестанты гибнут, не успев произнести почти ни слова и уж точно ни одного монолога. Возможно, это следствие дефектности дошедшего до нас текста пьесы - но вряд ли сцены Варфоломеевской ночи перебивались какими-то обширными фрагментами с второстепенной интригой. Неоднократно повторенный возглас, по-видимому, и должен был оставаться рефреном в быстро сменяющих друг друга сценах, где жертвы меняются, а преступники нет: 
GUISE. Tue, tue, tue,

Let none escape, murder the Hugonets.

(Marlowe, 1998: 332)

ANJOY. Kill them, kill them.

(ibid.: 339)

В поздних пьесах, напротив, жертва может быть вполне уверена, что гибель не означает итогового поражения. Для Эдуарда II, например, это вопрос «спасения имени», облегченный еще и тем, что сын его носит то же имя:

So shall not Englands Vine be perished,

But Edwards name survives, though Edward dies.

(Marlowe, 1994: 68)

Очевидно, что монарх и Англия - две составные части одного мистического тела, но этот акцент на спасении именно потомков Эдуарда и его (очерненного, как ему представляется) имени могут вполне разделить и зрители: да, Эдуард III отомстит Мортимеру, вырастет и станет великим королем.

Более сложный случай, например, мы видим в концовке «Резни», написанной, когда формально религиозные войны еще не закончились, но победа Генриха IV оставалась лишь вопросом времени. Смертельно раненый Генрих III через двойное посредничество английского посла и королевы Елизаветы, в сущности, обращается к зрителю, давая ему невыполненное (и невыполнимое, учитывая организационное бессилие последнего из Валуа) обещание:

Agent for England, send thy mistres word, What this detested Jacobin hath done. Tell her for all this that I hope to live, Which if I doe, the Papall Monarck goes

To wrack, and antechristian kingdome falles.

(Marlowe, 1998: 360) 
Он завершает речь восстановлением союзнических отношений, которых в реальности ждут уже от его преемника:

And heere protest eternall love to thee, And to the Queene of England specially, Whom God hath blest for hating Papestry.

(ibid.: 361)

Зрители, превращаясь в сообщество памяти, вероятно, надеялись, что так и произойдет, а Франция наконец перестанет быть анти-Англией, пространством хаоса и источником опасности.

Э. Кёрк несколько упрощает, изображая желание зрителя «англизировать» историю Франции, основываясь на противопоставлении «неправедного насилия по отношению к протестантам и козней против королевской власти... во Франции» (“the unjust violence against Protestants and the illegitimate machinations against royal power... in France”) и «ниспосланных свыше порядка и стабильности Англии» (“the providential order and stability of England”; Kirk, 1995: 194), но сам дополняет эту картину утверждением, что если где здесь и присутствует стабильность, то скорее в контроле драматурга над его текстом. Можно добавить, что и зрителя над историей.

Как точно указывает Ч. Форкер (Forker, 1996: 67), в «Эдуарде ІІ» (и как мы только что видели, также и в «Резне») Марло может позволить себе пророчество, которое рискует не сбыться или точно не сбудется. Королева Изабелла говорит сыну, что его качества заставляют опасаться за его долгую жизнь, но Марло, полагает Форкер, может позволить себе заимствовать сбывшееся предсказание Ричарда III Эдуарду V из шекспировской трагедии. Оно одновременно очернит Изабеллу и возвысит будущего великого короля Эдуарда, но главное - сообщество памяти нельзя обмануть.

В значительной степени границы исторической памяти этого сообщества помогает формировать и сам Марло - сжимает и растягивает ход событий. Так, смерть Жанны д’Альбре и ранение Колиньи разделяли не секунды, как на сцене, а два с половиной месяца. Герцог Кентский в «Ричарде II» не мог присутствовать на всех событиях вплоть до собственной гибели - в начале пьесы он должен был бы быть ребенком. Сам прием умолчания, когда после сцены 14 «Резни» мы перескакиваем из 1570-х в 1580-е гг., а также прием пристальной фиксации, когда в горизонт внимания драматурга попа- 
дает такое частное событие, как убийство Сен-Мегрена слугами Гиза ${ }^{2}$, доказывают, насколько автор властен над этой памятью (но и ему не под силу было бы превратить, например, Варфоломеевскую ночь в победу протестантов). Прав тот же Форкер, утверждая, что эти «необходимые сжатия времени, перестановки, упрощения и образные расширения эпизодов» (“necessitated compressions of time; rearrangements, simplifications, and imaginative expansions of episodes”; Forker, 1996: 77) определяются самим жанром³.

Итак, особое «сообщество памяти» составляют автор и зрители / читатели пьесы, его движущий механизм - избирательная «память поэта», которая (в развитие идеи Доллимора) одновременно сознательно дидактизирует историю и невольно выдает то, что современная теория травмы называет труднопереводимым в данном контексте словом “anxiety” - факторы беспокойства. Последние прежде всего связаны с боязнью переворотов, войн, резни, а в последнее елизаветинское десятилетие, когда конец династии стал делом ближайшего будущего, эти факторы не могли не усиливаться. Тем не менее странным было бы видеть в исторической хронике только канал пропаганды и социальных страхов. Этот жанровый процесс можно рассматривать и в целом как связанный с необходимостью постоянно соединять современность и историю.

Но отличие «поздних пьес» Марло от «ранних» еще и в том, что сообщество памяти присутствует внутри самой пьесы с самого начала и остается в ней до конца. Это пьесы, разбивающие волю того из воплощений и поклонников Макиавеля, кто пытается в ней стать «Цезарем». Overreacher подвергается новому виду деконструкции - его замыслы рушатся рутинно, а не потому, что он столкнулся с непреодолимой силой, как Тамерлан, Фауст и Ваpaвва.

Так, Карл, пытаясь сохранить верность данному гугенотам слову, апеллирует к международному мнению:

Madam, it wilbe noted through the world, An action bloudy and tirannicall...

(Marlowe, 1998: 328)

\footnotetext{
${ }^{2}$ В дошедшем до нас тексте Сен-Мегрен перепутан с другим миньоном Генриха III Можироном (см.: Макаров, 2019: Электронный ресурс).

${ }^{3}$ Который он, правда, считает созданием исключительно Шекспира - скорее, конечно, речь может идти об отличии «памяти историка» от «памяти поэта». В дальнейшем здесь необходимо более серьезное обращение к ренессансным поэтикам.
} 
Гиз, видя в себе нового Цезаря, покорителя мира, гибнет не от того, что достиг всех целей и теперь ему противостоит то, в схватке с чем нельзя победить: он нарывается на такой же спешно слепленный план убийства, каким была и Варфоломеевская ночь. Как отрицатель религии, он не может молиться, но сохраняет верность своей маниакальной цезарианской идее:

Now by the holy sacrament I sweare, As ancient Romanes over their Captive Lords, So will I triumph over this wanton King...

Yet Cœsar shall goe forth...

(ibid.: 353-354)

Исследователи отмечают, что при этом возникают симметрии и повторы, которые могут несколько изменить и общий пейзаж памяти. Так, Дж. Бриггс в работе об источниках «Резни» отмечает, что Марло переносит сцену убийства Гиза: в исторических текстах (и в реальности) Гиз был убит прежде, чем его мог бы принять король, а у Марло он возвращается с аудиенции, что дает возможность вспомнить, как Карл IX в начале пьесы посещает раненого Колиньи, обещая ему безопасность (“lulled into a state of false confidence by Henry’s treacherous reassurances” — Briggs, 1983: 265). Такое же подражание «ритуалу насилия» Бриггс видит в сценах с Джеком Кэдом в шекспировском (и марловском?) «Генрихе VI» (ibid: 274), а самое главное в заключительной сцене, где смертельно раненый Генрих обещает так же изничтожить Папу и его последователей, как призывал умирающий Гиз:

Ah Sextus, be reveng'd upon the King, Philip and Parma, I am slaine for you... Vive la messe, perish Hugonets...

(Marlowe, 1998: 354)

Эта «подозрительно ироничная» симметрия (Briggs, 1983: 274), скорее всего, действительно предполагает, что без новой Варфоломеевской ночи план Генриха III не осуществить. Аналогично Кёрк указывает на симметрию в поступках Гиза и Генриха Наваррского (Kirk, 1995: 208-209) - оба ждут, не раскрывают свои истинные планы до подходящего момента, и лишь молитва и упование на то, что Бог раскроет ему этот план, отличает второго от 
первого с его раздосадованным восклицанием: “Religion? O Diabole!” (Marlowe, 1998: 325) ${ }^{4}$.

Наконец, важно отметить и функцию молчания (хотя мы можем ее понимать неточно из-за утрат в тексте «Резни»). Чем ближе жертва к смерти, тем меньше ей оставлено слов (см. об этом: Poole, 1998: 5-6). К. Пул видит в этом «скоростном убийстве» гугенотов сознательное изображение абсурда и жестокости насилия, но можно интерпретировать сцены Варфоломеевской ночи и иначе: гугеноты говорят мало, но главное - молитву, а остальные персонажи в избыточности речи либо прячут неспособность управлять (Карл IX), либо обнаруживают жестокость (Гиз, королева Екатерина, Генрих Анжуйский). Правда, при этом гугеноты - даже Колиньи - действительно не являются политическими акторами.

В этом же ключе М. Мартин рассматривает и крики Эдуарда II в момент его убийства — как сведение речи к боли (Martin, 2016: 123; здесь можно добавить: а жизни - к «голому существованию» по Агамбену). Однако Мартин неправ, думая, что лишь новая травма как воспоминание о старой действует на зрителя. Жестокое насилие, тем более примененное к королю, скорее окончательно стирает из памяти картины его ошибок и грехов и делает его смерть действительно «достойной печали» (lamentable), о чем - по крайней мере читателю - было сказано уже в заглавии.

Любопытно, что основы такого подхода к «поздним пьесам» Марло заложил еще Г. Левин, в целом остававшийся в рамках интерпретации героев Марло как overreacher’ов. Так, об «Эдуарде II» он в итоге говорит, что в такой «трагической жизни не нужны злодеи... каждый [в итоге] выдает себя сам» (“tragic life needs no villains... men betray themselves”; Levin, 1952: 82). В череде фаворитов Эдуарда II, которых Марло сознательно делает трудноотличимыми, взаимоозлобление между королем, фаворитами и придворными возрастает так, что трудно определить, от кого оно все же исходит. Гавестон показывает «новый и опасный путь <социального> взлета» (“а new and dangerous way to rise in the world”; ibid.: 91), но он слишком короток и мимолетен и заканчивается не на высшей ноте успеха, за которой падение неизбежно.

И. Рибнер прав, указывая на схожий момент в изображении структур власти в «Тамерлане» и «Эдуарде II» - Марло сознательно игнорирует проблемы божественного права королей (Ribner, 2005: 129), но в остальном это

\footnotetext{
4 Здесь можно отметить и двойной английский смысл имени Guise - «маска», «личина».
} 
очень разные структуры. Атомизированный, полный частных стратегий и личных интересов мир «Тамерлана» совсем не похож на конкурентный и непредсказуемый своими стратегическими союзами мир английского двора начала XIV в. В «Тамерлане» ясно, что бич Божий не победить и можно только не попасть под него по какой-то причине. В «Эдуарде» альянсы меняются постоянно, и в падении и казни героев нужно уметь видеть некую логику истории. Или хотя бы полагаться на историческую память.

\section{ЗАКЛЮЧЕНИЕ}

В заключение несколько слов о «травматичности» этой истории. Разумеется, чем ближе к Англии и чем больше в марловском тексте не абстрактного «христианства», на которое из степей Малой Азии глядит Тамерлан, а конкретной религиозной борьбы католиков и протестантов, тем эта травма сильнее. Для лондонских театралов Марло (или его соавторы) готовит вечно жестокое напоминание о Риме (деспотичной тюрьме, из которой Фауст и Мефистофель спасают антипапу Бруно, или бездонного сундука, откуда Гизу идут подарки и пенсион). Но чем ближе к реальному насилию - Варфоломеевской ночи, красочно описанной в источниках Марло или «Книге мучеников» Джона Фокса, или к бессудной казни Гэвестона, или к унижению и убийству Эдуарда - тем более актуальным становится термин М. Мартина — «травматический реализм». Не погружаясь в современную trauma theory, Мартин видит в нем «рану», экстремальный вариант “anxiety”. Это вполне марловское понимание - его героев ранить может даже имя:

EDWARD. Mortimer, who talkes of Mortimer,

Who wounds me with the name of Mortimer

That bloudy man?

$$
\text { (Marlowe, 1994: 64) }
$$

Рассказанные в обеих «поздних пьесах» истории намного более травматичны, и тем сильнее эта «рана», что ее причиной нельзя считать только Гэвестона и Гиза или Карла и Генриха Валуа и Эдуарда Плантагенета. Новое и новое воспроизведение травмы на театральной сцене - следствие работы памяти. Травма болезненна, но память, воспроизводимая на сцене и в уме, сильнее, чем сиюминутная жанровая и политическая конъюнктура. Возможно, травму смягчает крайне быстрое развитие театра как искусства, а также эволюция и смена жанровых предпочтений. 


\section{СПИСОК ЛИТЕРАТУРЫ}

Захаров, Н. В. (2018) Образ Кристофера Марло и псевдобиографический под-ход в современной массовой культуре [Электронный ресурс] // Горизонты гуманитарного знания. № 3. C. 62-71. URL: http://journals.mosgu.ru/ggz/article/view/798 (дата обращения: 25.11.2019). DOI: 10.17805/ggz. 2018.3.4

Макаров, В. С. (2018а) «Трагическая история доктора Фауста»: вопросы датировки и издания [Электронный ресурс] // Горизонты гуманитарного знания. № 6. C. 20-34. URL: http://journals.mosgu.ru/ggz/article/view/894 (дата обращения: 25.11.2019). DOI: 10.17805/ggz.2018.6.2

Макаров, В. С. (2018b) Комментарий к пьесе К. Марло «Эдуард ІІ» [Электронный ресурс] // Современники Шекспира: Информационно-исследовательская база данных. URL: http://around-shake.ru/file.php/id/f5189/name/Edward II Commentaries.pdf [архивировано в WaybackMachine] (дата обращения: 25.11.2019).

Макаров, В. С. (2019) <Комментарий к трагедии «Парижская резня»> [Электронный ресурс] // Современники Шекспира: Информационно-исследовательская база данных. URL: http://around-shake.ru/file.php/id/f5336/name/Massacre-at-Paris Commentaries.pdf [архивировано в WaybackMachine] (дата обращения: 25.11.2019).

Briggs, J. (1983) Marlowe's "Massacre at Paris": A reconsideration // The Review of English Studies. Vol. 34. No. 135. P. 257-278.

Craig, H. (2009) The three parts of "Henry VI" // Shakespeare, computers, and the mystery of authorship / ed. by H. Craig, A. F. Kinney. Cambridge : Cambridge University Press. xix, 234 p. P. 40-77.

Dollimore, J. (1994) Introduction: Shakespeare, cultural materialism, and the new historicism // Political Shakespeare: New essays in cultural materialism / ed. by J. Dollimore, A. Sinfield. 2nd edn. Ithaca, NY ; L. : Cornell University Press. viii, 295 p. P. 2-17.

Forker, C. R. (1996) Marlowe's “Edward II” and its Shakespearean relatives: The emergence of a genre // Shakespeare's English histories: A quest for form and genre / ed. by J. W. Velz. Tempe, AZ : Medieval \& Renaissance Texts \& Studies. viii, 267 p. P. 55-90.

Freebury-Jones, D. (2017) Did Shakespeare really co-write "2 Henry VI" with Marlowe? // ANQ: A Quarterly Journal of Short Articles, Notes and Reviews. Vol. 30. No. 3. P. 137-141. DOI: $10.1080 / 0895769 X .2017 .1295360$ 
Kirk, A. M. (1995) Marlowe and the disordered face of French history // Studies in English Literature, 1500-1900. Vol. 35. No. 2: Tudor and Stuart Drama. P. 193-213.

Levin, H. (1952) The overreacher: A study of Christopher Marlowe. Cambridge : Harvard University Press. xiii, [3], 204 p.

Marlowe, C. (1994) The complete works of Christopher Marlowe. Oxford : Clarendon Press ; N. Y. : Oxford University Press. Vol. 3: Edward II / ed. by R. Rowland. xxxvii, 150 p. DOI: 10.1093/actrade/9780198122784.book.1

Marlowe, C. (1995) The complete works of Christopher Marlowe. Oxford : Clarendon Press ; N. Y. : Oxford University Press. Vol. 4: The Jew of Malta / ed. by R. Gill. xx, 127 p. DOI: 10.1093/actrade/9780198127703.book.1

Marlowe, C. (1998) The complete works of Christopher Marlowe. Oxford : Clarendon Press ; N. Y. : Oxford University Press. Vol. 5: Tamburlaine the Great, Parts 1 and 2, and The Massacre at Paris with the Death of the Duke of Guise / ed. by D. Fuller and E. J. Esche. liii, 406 p. DOI: 10.1093/actrade/9780198183204. book.1

Martin, M. R. (2016) Tragedy and trauma in the plays of Christopher Marlowe. L. ; N. Y. : Routledge, Taylor \& Francis Group. viii, 194 p.

Poole, K. E. (1998) Garbled martyrdom in Christopher Marlowe's "The Massacre at Paris” // Comparative Drama. Vol. 32. No. 1. P. 1-25. DOI: 10.1353/ cdr.1998.0044

Ribner, I. (2005) The English history play in the age of Shakespeare. L. ; N. Y. : Routledge, Taylor \& Francis Group. xii, 356 p.

Wiggins, M. (2000) Shakespeare and the drama of his time. Oxford ; N. Y. : Oxford University Press. 149 p.

Дата поступления: 24.10.2019 г.

\section{REFERENCES}

Zakharov, N. V. (2018) Obraz Kristofera Marlo i psevdobiograficheskii podkhod v sovremennoi massovoi kulture [The image of Christopher Marlowe and the pseudo-biographical approach in contemporary mass culture]. Gorizonty gumanitarnogo znaniia, no. 3, pp. 62-71. [online] Available at: http://journals. mosgu.ru/ggz/article/view/798 (accessed 25.11.2019). (In Russ.). DOI: 10.17805/ ggz.2018.3.4 
Makarov, V. S. (2018a) «Tragicheskaia istoriia Doktora Fausta»: Voprosy datirovki i izdaniia [“The Tragical History of Doctor Faustus”: Dating and publication]. Gorizonty gumanitarnogo znaniia, no. 6, pp. 20-34. [online] Available at: http://journals.mosgu.ru/ggz/article/view/894 (accessed 25.11.2019). (In Russ.). DOI: $10.17805 /$ ggz.2018.6.2

Makarov, V. S. (2018b) Kommentarii k p'ese K. Marlo «Eduard II» [A commentary to C. Marlowe's play “Edward II”]. Sovremenniki Shekspira: Informatsionno-issledovatel'skaia baza dannykh [online] Available at: http://aroundshake.ru/file.php/id/f5189/name/Edward II Commentaries.pdf [archived in WaybackMachine] (accessed 25.11.2019) (In Russ.).

Makarov, V. S. (2019) <Kommentarii k tragedii «Parizhskaia reznia»> [A commentary to tragedy "The Massacre at Paris"]. Sovremenniki Shekspira: Informatsionno-issledovatel'skaia baza dannykh [online] Available at: http://aroundshake.ru/file.php/id/f5336/name/Massacre-at-Paris Commentaries.pdf [archived in WaybackMachine] (accessed 25.11.2019) (In Russ.).

Briggs, J. (1983) Marlowe's Massacre at Paris: A reconsideration. The Review of English Studies, vol. 34, no. 135, pp. 257-278.

Craig, H. (2009) The three parts of "Henry VI". In: Shakespeare, computers, and the mystery of authorship / ed. by H. Craig, A. F. Kinney. Cambridge : Cambridge University Press. xix, 234 p. Pp. 40-77.

Dollimore, J. (1994) Introduction: Shakespeare, cultural materialism, and the new historicism. In: Political Shakespeare: New essays in cultural materialism / ed. by J. Dollimore, A. Sinfield. 2nd edn. Ithaca, NY ; London : Cornell University Press. viii, 295 p. Pp. 2-17.

Forker, C. R. (1996) Marlowe's "Edward II” and its Shakespearean relatives: The emergence of a genre. In: Shakespeare's English histories: A quest for form and genre / ed. by J. W. Velz. Tempe, AZ : Medieval \& Renaissance Texts \& Studies. viii, 267 p. Pp. 55-90.

Freebury-Jones, D. (2017) Did Shakespeare really co-write "2 Henry VI" with Marlowe? ANQ: A Quarterly Journal of Short Articles, Notes and Reviews, vol. 30, no. 3, pp. 137-141. DOI: 10.1080/0895769X.2017.1295360

Kirk, A. M. (1995) Marlowe and the disordered face of French history. Studies in English Literature, 1500-1900, vol. 35. no. 2: Tudor and Stuart drama, pp. 193-213.

Levin, H. (1952) The overreacher: A study of Christopher Marlowe. Cambridge : Harvard University Press. xiii, [3], 204 p. 
Marlowe, C. (1994) The complete works of Christopher Marlowe. Oxford : Clarendon Press ; New York : Oxford University Press. Vol. 3: Edward II / ed. by R. Rowland. xxxvii, 150 p. DOI: 10.1093/actrade/9780198122784.book.1

Marlowe, C. (1995) The complete works of Christopher Marlowe. Oxford : Clarendon Press ; New York : Oxford University Press. Vol. 4: The Jew of Malta / ed. by R. Gill. xx, 127 p. DOI: 10.1093/actrade/9780198127703.book.1

Marlowe, C. (1998) The complete works of Christopher Marlowe. Oxford : Clarendon Press ; New York : Oxford University Press. Vol. 5: Tamburlaine the Great, Parts 1 and 2, and The Massacre at Paris with the Death of the Duke of Guise / ed. by D. Fuller and E. J. Esche. liii, 406 p. DOI: 10.1093/actrade/9780198 183204.book.1

Martin, M. R. (2016) Tragedy and trauma in the plays of Christopher Marlowe. London ; New York : Routledge, Taylor \& Francis Group. viii, 194 p.

Poole, K. E. (1998) Garbled martyrdom in Christopher Marlowe's “The Massacre at Paris”. Comparative Drama, vol. 32, no. 1, pp. 1-25. DOI: 10.1353/ cdr.1998.0044

Ribner, I. (2005) The English history play in the age of Shakespeare. London ; New York : Routledge, Taylor \& Francis Group. xii, 356 p.

Wiggins, M. (2000) Shakespeare and the drama of his time. Oxford ; New York : Oxford University Press. 149 p.

Submission date: 24.10.2019.

Макаров Владимир Сергеевич - кандидат филологических наук, доцент кафедры германской филологии Православного Свято-Тихоновского гуманитарного университета. Адрес: 109651, Россия, г. Москва, ул. Иловайская, д. 9, корп. 2. Тел.: +7 (495) 646-71-38. Эл. адрес: mail@vmakarov.name

Makarov Vladimir Sergeevich, Candidate of Philology, Associate Professor, Department of Germanic Philology, St. Tikhon's Orthodox University. Postal address: Bldg. 2, 9 Ilovaiskaya St., 109651 Moscow, Russian Federation. Tel.: +7 (495) 646-71-38. E-mail: mail@vmakarov.name 
Для изитирования:

Макаров В. С. От трагического героя к травматической истории: к проблематике позднего К. Марло («Эдуард II», «Парижская резня») [Электронный ресурс] // Горизонты гуманитарного знания. 2019. № 6. С. 26-42. URL: http://journals.mosgu.ru/ggz/article/view/1090 (дата обращения: дд.мм. гггг). DOI: 10.17805/ggz.2019.6.2 